\title{
Pseudo-Tumoral Calcinosis: A Rare Condition in Chronic Hemodialysis. About A Case
}

\author{
Amine El Masloumi ${ }^{1 *}$, Christ Labretesche Gakosso ${ }^{2}$, Hajar Saffour ${ }^{3}$, Badr Boutakioute $^{4}$, Meriem Ouali Idrissi ${ }^{5}$, Najat \\ Idrissi El Ganouni ${ }^{6}$

\footnotetext{
${ }^{1,2}$ Radiology Department, Student in Radiology, Arrazy hospital ,Mohammed VIth teaching center,Cadi Ayad University, Marrakesh, Morocco

${ }^{3}$ Student in Biology Medical Biology Department, Mohammed VI University Hospital, Marrakech Faculty of Medicine and Pharmacy, Cadi Ayyad University, Marrakech Morocco

${ }^{4,5,6}$ Professor in Radiology, Radiology Department, Arrazy hospital ,Mohammed VIth teaching center , Cadi Ayad University , Marrakesh, Morocco
}

Tumor calcinosis is a rare, well-defined clinical entity characterized by the deposition of calcium material in the periarticular soft tissues taking tumor form. Diagnosis is most often made by imaging. We report the case of a 43 -yearold chronic hemodialysis patient with a swelling of the right shoulder that has progressively progressed over the past 3 months. The CT scan of the shoulder allowed the diagnosis of pseudo tumoral calcinosis to be made and the anatomopathological study confirmed it after surgical removal.

Keywords: pseudotumoral calcinosis; chronic hemodialysis; imaging.

Copyright @ 2020: This is an open-access article distributed under the terms of the Creative Commons Attribution license which permits unrestricted use, distribution, and reproduction in any medium for non-commercial use (NonCommercial, or CC-BY-NC) provided the original author and source are credited.

\section{INTRODUCTION}

Tumor-like calcinosis (TPC) is a condition characterized by the deposition of calcium phosphate crystals in the periarticular soft tissues, sometimes resulting in large calcified tumor-like masses that limit limb movement [1,2]. Although the physiopathogenesis of DTCs is not fully understood, the increase in phosphocalcium product above the precipitation threshold and severe hyper parathyroidism seem to play a decisive role [3]. In renal insufficiency patients under haemodialysis, the frequency of DTC is estimated to be between 0.5 and $7 \%$ depending on the series [4].

\section{OBSERVATION}

We report the case of a 43-year-old patient who consulted the trauma department at the Arrazi hospital at the Mohamed VI University Hospital in Marrakech for a swelling of the right shoulder that has been progressively progressing for 3 months. Physical examination showed a fixed and not very painful mass of the left shoulder with a limitation of upper limb movements with obvious alteration of muscular forces (1/ 5). The patient is being followed for type I diabetes, in chronic end-stage renal failure at the haemodialysis stage. A tumor origin was initially suspected and a CT scan of the shoulder and thoraco-abdomino-pelvic were requested. CT scan of the shoulder showed a giant calcified, multiloculate popcorn mass surrounding the right shoulder associated with multiple subacromial and deltoid cystic lesions, surrounded by a calcified borderline, with liquid-liquid levels related to sedimentation deposits .Thoraco-abdomino-pelvic CT scan showed a second mass in the soft tissues having the same characteristics as the above described mass. It also showed multiple staged somatic spinal lesions with alternating zones of condensation and other lytic "Rugby Shirt" lytics. In front of the characteristic radiological aspect, bilateral pseudotumoral calcinosis has been evoked with spinal lesions of renal osteodystrophy. A hyperphosphatemia with hypocalcaemia and hypercalciuria with high alkaline phosphatase levels, creatinine $35 \mathrm{mg} / 1$ was observed. The right shoulder mass was surgically removed and histo-pathology showed hydroxyapatite crystals with appearance of synovitis. No recurrence was not dafter a 6-month follow-up, so for the left shoulder mass, the decision of the surgeons was to abstain from therapy due to its asymptomatic nature.

\section{Etiopathogeny:}

It occurs in two clinical forms: the sporadic form, secondary to a chronic disease $[5,6]$ and the primitive form called familial, probably genetic in origin. The secondary form is most often found in patients with chronic renal failure and in these cases, 
calcium deposition is linked to an abnormality of phosphocalcic metabolism [3]. The primary form, on the other hand, is probably of genetic origin by autosomal recessive transmission [3] and is responsible for familial hyperphosphatemia due to enzymatic disruption without associated renal failure and, according to some authors, is the prerogative of the African subject with large periarticular masses during the first decade of life [7].Our patient had a secondary form because he had chronic kidney failure. The pathophysiology of pseudo tumoral calcinosis has not yet been fully elucidated. Some the authors report that the increase in phosphocalcium product bove the precipitation threshold, as well as severe hyperparathyroidism, may play a determining role. Repetitive joint trauma may also play a role. In dialysis subjects, as in our observation, the frequency of CPT is estimated to be between 0.5 and $7 \%$ depending on the series. 8] This could be explained by the effects due to hyperparathyroidism, which would be an unavoidable complication of chronic kidney disease. Excess parathyroid hormone stimulates bone resorption and thus increases serum calcium and phosphorus levels, which are thought to promote soft tissue crystal deposition that may explain the long-term manifestations of CPT [9].

\section{Clinical manifestations}

The periarticular mass is usually painless, but very often there is a significant limitation of joint mobility depending on the location [7]. In our patient, the mass was located in the right shoulder and was indeed painless, with limited joint movement. It may be come symptomatic in some localization and may become painful by compression of the surrounding structures or functional gene. In most cases the preoperative diagnosis is not always obvious, with the haunting for any surgeon to know me a malignant tumor. The biological assessment is often normal [10]. Nevertheless, disturbances of the phospho-calcium balance can be observed.

\section{Imaging}

The standard radiographic the first-line examination and it allows the diagnosis to be evoked by showing juxtaposed articular calcifications producing a clustered appearance by juxtaposition of small dense, rounded and well-limited homogeneous images, separated by radio-transparent septa [3, 11]; this calcification developed by sedimentation producing a mass most often heterogeneous to the classical honeycomb image $[3,12]$. The characterization of the lesions and the determination of its relationship with the musculoskeletal and osseous structures is done by CT or even MRI. CT shows masses of high density with pseudo cysts, separated by fibrous septa with liquid levels that show the "sedimentation sign" [13].CT scanning also helps to determine the extent and ratios of these lesions and assists in surgical planning [3].In some cases, lesions may appear dense and homogeneous $[14,15]$. Erosion and bone destruction by adjacent soft tissue masses is systematically absent [16]. The ultra sound appearance is poorly described in the literature, however, according to some authors, the lesions appear as multi localized masses with a calcified shell and fluid content [12]. Magnetic resonance imaging (MRI) remains the most efficient examination. It reveals multiple masses that can infiltrate the adjacent muscles, organized in calcified pockets, which appear hyper intense in T2, and hypo intense in T1 due to the inflammatory component. A less intense appearance in $\mathrm{T} 2$ is observed in the case of metabolic stable lesions. There are hyper-intense $\mathrm{T} 1$ and $\mathrm{T} 2$ areas around the lesion in relation to fatty is lets. A cystic component with liquid-liquid- calves within the cavities is sometimes observed. Technetium-pyrophosphate scintigraphy would show hyper fixation of the pseudo tumor $[11,12]$.

\section{Anatomy-pathology}

Although it is preferable to avoid biopsy for fear of infection [17].It can still be done in difficult cases to settle diagnosis [18]. Histopathological examination of CT lesions after biopsy or surgical excision shows some characteristic morphological features that differentiate it from other calcification processes.

\section{Differential diagnosis}

It arises with all processes leading to soft tissue calcium deposition including: osteosarcoma, chondrosarcoma, gout tophus, ossifying myositis. This can be resolved by combining the typical radiological features of the CT with the serum biochemical profile (including serum calcium, phosphorus, renal function, serum parathyroid hormone and 1, 25-dihydroxyvitamin D [19].

\section{Treatment}

Complete surgical excision is the rule for any pseudo tumourous calcinosis that be comes symptomatic due to its volume and/or location [3]. Surgical treatment consists of complete removal of the lesion to ensure that the tumour does not recur. The definitive diagnosis is histopathological through a surgical biopsy for fear of my identifying malignant tumour. Incomplete removal of the lesion will lead to tumour recurrence. The post-operative course is generally simple and the prognostic is remains good. [3]. Never the less, there is a high rate of recurrence, specially after incomplete resection and in patients with secondary hyper-parathyroidism [11]. 


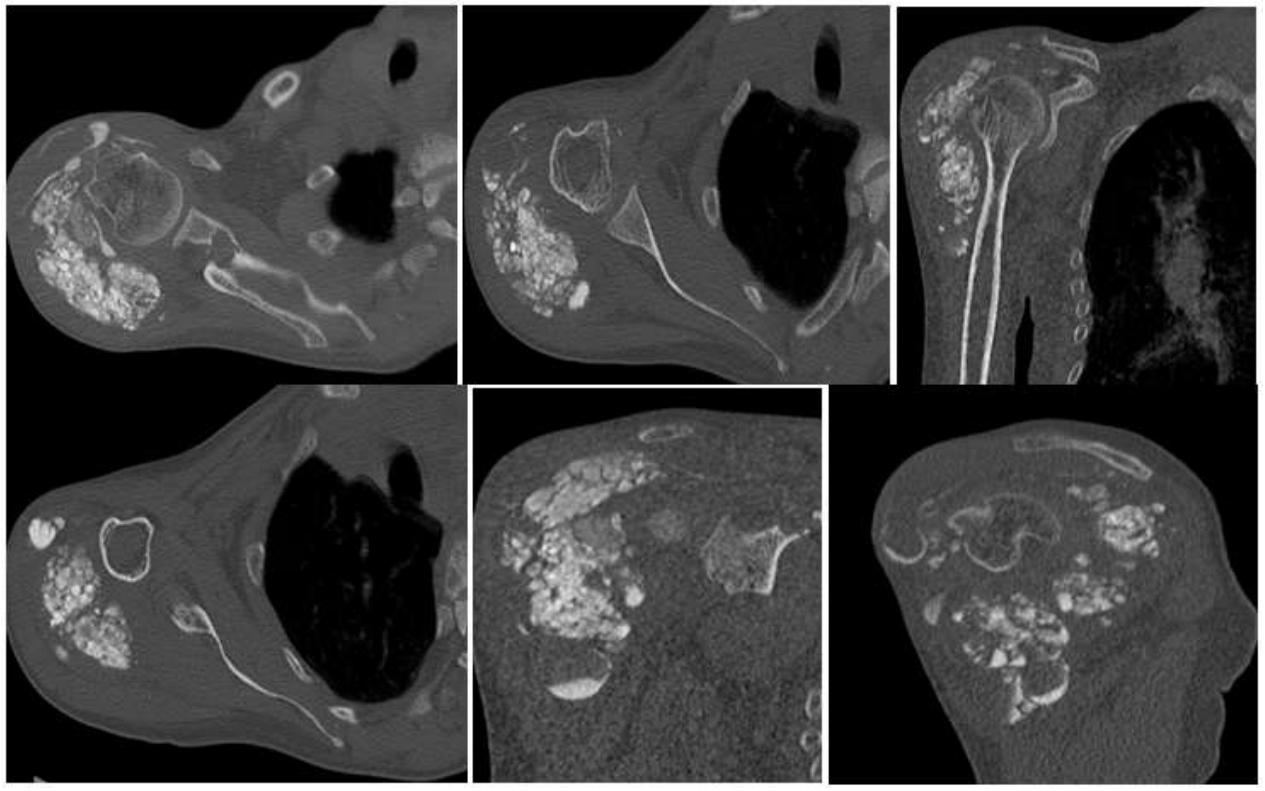

Figure 1: CT scan of the right shoulder-bone window-axial, coronal and sagittal Sections: voluminous calcified clustered periarticular soft tissue mass with individualization of bone erosion at the infra glenoid tubercle. Presence of liquid-liquid levels with dense sediment associated with multiple cystic lesions underacromio-deltoid and deltoid, surrounded by a calcified edging, with levels of liquid-liquids related to sedimentation deposits.

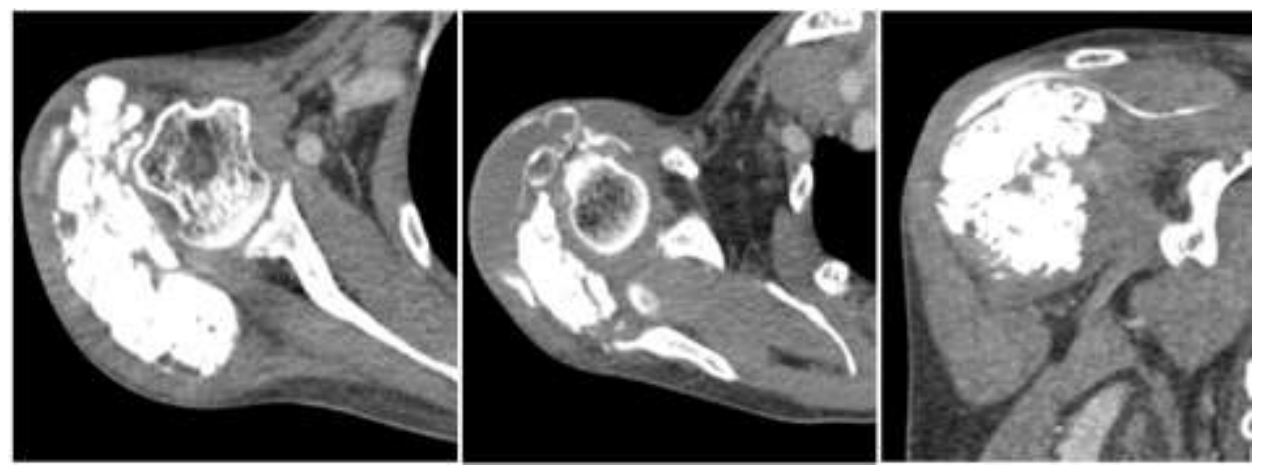

Figure 2: CT scan of the right shoulder - soft tissue window: large mass calcified clustered periarticular soft tissues, measuring 10x4x11 cm, occupying the right deltoid region along the metaphyseal-diaphyseal region of humerus, synovit is under acromio-deltoid and deltoid synovitis, surrounded by; calcified edging, seat of liquid-liquid levels.
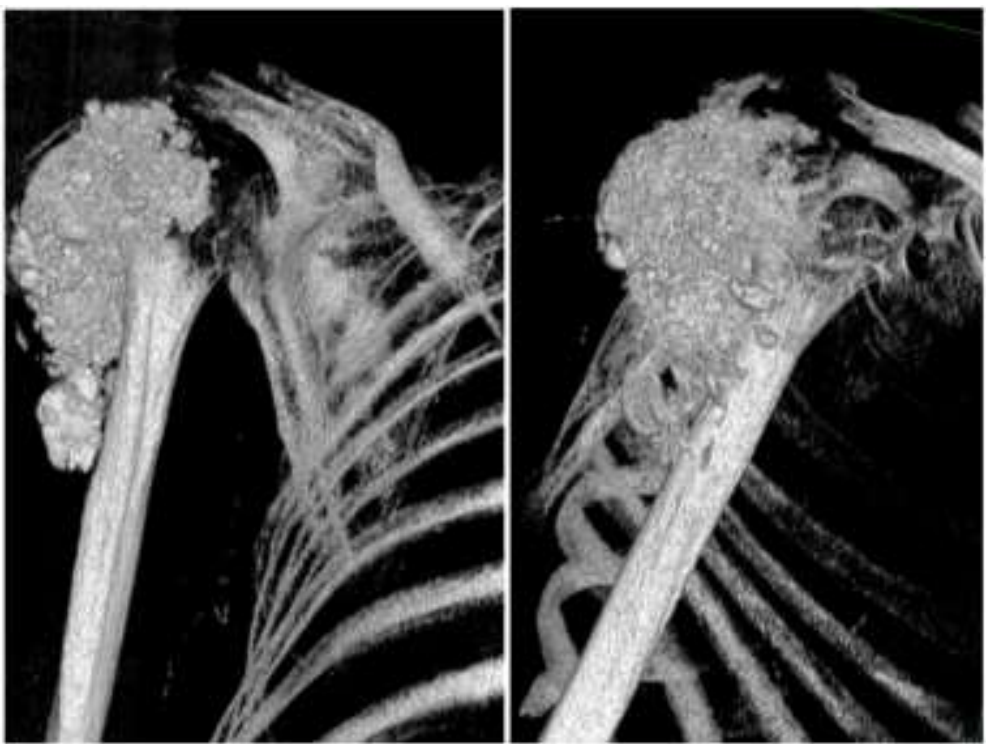

Figure 3: CT scans of the right shoulder - 3D reconstruction: voluminous mass of the parts calcified popcorn periarticular soft tissues. 


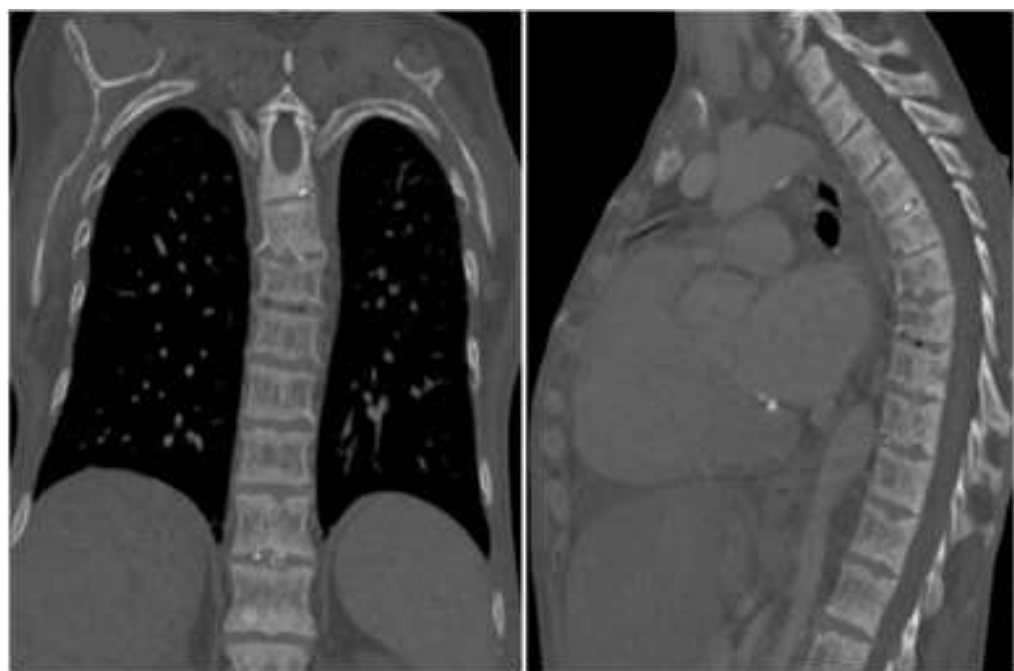

Figure 4: Thoracic CT scan-bony window: multiple staged somatic spinal lesions with alternating zones of condensation and other lytics made in "Rugby Shirt": renal osteodystrophy.

\section{Conclusion}

Pseudo tumoral calcinosis is a rare entity that can be primary or secondary, and whose radiographic appearance is characteristic on conventional radiology and then on CT and MRI. The treatment is surgical and the prognosis is always favorable.

\section{RÉFÉRENCES}

1. McClatchie S, Bremner AD. Tumoralcalcinosis--an unrecognizeddisease. Br Med J. 1969; 1: 153-155

2. Lafferty FW, Reynolds ES, Pearson $\mathrm{OH}$. Tumoralcalcinosis: ametabolicdisease of obscure etiology. Am J Med. 1965; 38: 105-118

3. Harouna AD, Atarraf K, Afifi AM. Calcinose pseudo-tumorale primitive chez l'enfant. Pan AfricanMedical Journal. 2017;28(1).

4. Ibrahim Fathi, Mahmoud Sakr World J Clin Cases. 2014 September 16; 2(9): 409-414 ISSN 23078960.

5. Maghraoui JE, Hammou M, Kabbali N, Arrayhani M, Houssaini TS. Amélioration de la calcinose tumorale de la main droite après para thyroïdectomie chez un hémodialysé chronique. Pan Afr Med J. 2016; 24: 30.

6. Jellouli M, Gargah T. Tumoralcalcinosis in a patient on hemodialysis. Pan Afr Med J. 2016;23:155.

7. Toubeau A, Malasi S, Sarbu N. PseudotumoralCalcinosisFollowingBone Fracture. Journal of the Belgian Society of Radiology. 2019;103(1).

8. Kabbali N, Sqalli T. Pseudotumoralcalcinosis in a patient on chronichemodialysis. The Pan Africanmedical journal. 2017;28:250-.

9. P Urena Torres. Hyperparathyroïdie de l'insuffisance rénale.SFE Toulouse 2012/ Annales d'endocrinologie.2012; 73: 238 - 42.
10. Ngo S, Vandhuick T, Janvresse A, Levesque H, Marie I. Des calcifications pseudotumorales. Rev Médecine Interne. 2011 Apr;32(4):251-2.

11. En-Nafaa I, Africha T, Boussouga M, Semlali S, Chaouir S, Amil T, Hanine A. La calcinose tumorale: à propos d'un cas. Archives de pédiatrie. 2010 Aug 1;17(8):1165-8.

12. Şenol U, Karaali K, Çevikol C, Dinçer A. MR imagingfindings of recurrent tumoral calcinosis. Clinicalimaging. 2000 May 1;24(3):154-6.

13. Favia G, Lacaita MG, Limongelli L, Tempesta A, Laforgia N, Cazzolla AP, Maiorano E. Hyperphosphatemic familial tumoral calcinosis: odontostomatologic management and pathologicalfeatures. The American journal of case reports. 2014;15:569.

14. Hug I, Gunçaga J. Tumoralcalcinosiswithsedimentationsign. $\mathrm{Br} \quad \mathrm{J}$ Radiol. 1974; 47: 734-736

15. Harkess JW, Peters HJ. Tumoralcalcinosis. A report of six cases. J Bone Joint Surg Am. 1967; 49: 721-731

16. Martinez S, Vogler JB, Harrelson JM, Lyles KW. Imaging of tumoralcalcinosis: new observations. Radiology. 1990; 174: 215-222

17. Olsen KM, Chew FS. Tumoralcalcinosis: pearls, polemics, and alternative possibilities. Radiographics. 2006; 26: 871-885

18. Farzan M, Farhoud AR. Tumoral calcinosis: whatis the treatment? Report of two cases of different types and review of the literature. Am J Orthop (Belle Mead NJ). 2011 Sep;40:E170-6.

19. Petscavage JM, Richardson ML. Tumoralcalcinosismimickingrecurrentosteosarcom a. J Radiol Case Rep. 2009; 4: 336. 